\title{
Band-Engineered Structural Design of High-Performance Deep-Ultraviolet Light-Emitting Diodes
}

\author{
Jih-Yuan Chang ${ }^{1}$, Man-Fang Huang ${ }^{2}$, Chih-Yung Huang ${ }^{3}$, Shih-Chin Lin ${ }^{3}$, Ching-Chiun Wang ${ }^{3}$ \\ and Yen-Kuang Kuo $4, *$ (D) \\ 1 Center for Teacher Education, National Changhua University of Education, Changhua 500, Taiwan; \\ jihyuan67@gmail.com \\ 2 Institute of Photonics, National Changhua University of Education, Changhua 500, Taiwan; \\ mfhuang@cc.ncue.edu.tw \\ 3 Mechanical and Mechatronics Systems Research Laboratory, Industrial Technology Research Institute (ITRI), \\ Hsinchu 310, Taiwan; huangcy@itri.org.tw (C.-Y.H.); shihchin@itri.org.tw (S.-C.L.); \\ juin0306@itri.org.tw (C.-C.W.) \\ 4 Department of Physics, National Changhua University of Education, Changhua 500, Taiwan \\ * Correspondence: ykuo@cc.ncue.edu.tw; Tel.: +886-4-723-2110; Fax: +886-4-726-2739
}

Citation: Chang, J.-Y.; Huang, M.-F.; Huang, C.-Y.; Lin, S.-C.; Wang, C.-C.; Kuo, Y.-K. Band-Engineered

Structural Design of

High-Performance Deep-Ultraviolet Light-Emitting Diodes. Crystals 2021 11, 271. https://doi.org/10.3390/ cryst11030271

Academic Editor: Julien Brault

Received: 27 January 2021

Accepted: 7 March 2021

Published: 10 March 2021

Publisher's Note: MDPI stays neutral with regard to jurisdictional claims in published maps and institutional affiliations.

Copyright: (c) 2021 by the authors. Licensee MDPI, Basel, Switzerland. This article is an open access article distributed under the terms and conditions of the Creative Commons Attribution (CC BY) license (https:// creativecommons.org/licenses/by/ $4.0 /)$.
Abstract: In this study, systematic structural design was investigated numerically to probe into the cross-relating influences of $\mathrm{n}-\mathrm{AlGaN}$ layer, quantum barrier $(\mathrm{QB})$, and electron-blocking layer (EBL) on the output performance of AlGaN deep-ultraviolet (DUV) light-emitting diodes (LEDs) with various $\mathrm{Al}$ compositions in quantum wells. Simulation results show that high-Al-composition QB and high-Al-composition EBL utilized separately are beneficial for the enhancement of carrier confinement, while the wall-plug efficiency (WPE) degrades dramatically if both high-Al-composition QB and EBL are existing in a DUV LED structure simultaneously. DUV LEDs may be of great optical performance with appropriate structural design by fine-tuning the material parameters in n-AlGaN layer, QB, and EBL. The design curves provided in this paper can be very useful for the researchers in developing the DUV LEDs with a peak emission wavelength ranging from $255 \mathrm{~nm}$ to $285 \mathrm{~nm}$.

Keywords: AlGaN; carrier confinement; polarization effect; light-emitting diodes

\section{Introduction}

In $\mathrm{AlGaN}$ deep-ultraviolet (DUV) light-emitting diodes (LEDs), there are several critical challenges including lack of lattice-matched substrate, nature of lattice-mismatched AlGaN material system, and difficulty of sufficient hole activation in high-Al-composition p-AlGaN layers [1-4]. The present effort in developing AlGaN DUV LEDs concentrates mainly on the development of epitaxy technology to achieve high-quality epitaxial devices. Moreover, low light extraction efficiency due mainly to the massive transverse magnetic (TM) emission and absorbing layers is another critical issue that may cause degrading the external quantum efficiency (EQE) of DUV LEDs [5,6]. Recently, 2D material-assisted remote epitaxy of AlGaN LED has been widely studied to address the issues in epitaxy technology [7,8]. Several efforts have also been made in an attempt to resolve the issue of light extraction [9-11]. Moreover, research has also been dedicated to the heterostructure design of the multi-quantum well (MQW) and electron-blocking layer (EBL) with simulation as well as experimental study $[12,13]$. However, a thorough study on structural design of the DUV LEDs, which may severely affect the output performance of DUV LEDs, is still demanded. In the counterparts of InGaN visible and near-ultraviolet (NUV) LEDs, most of the structure layers including basal layer, barrier layers of MQW active region, and contact layer are GaN binary material, which provides sufficient support to the lattice-mismatched InGaN quantum wells (QWs) and AlGaN EBL. As for the AlGaN DUV LEDs, dissimilar to InGaN LEDs, the criteria for structural design are still under investigation, which leaves 
possibilities for upgrading the output performance of DUV LEDs through appropriate structural design.

In typical LEDs, layers within or neighboring the MQW active region are very critical areas affecting the output performance. In our previous studies, the mechanism of carrier transport in p-type layers was theoretically investigated, which revealed that the large potential barrier in the valence band of heterojunctions could be a critical issue obstructing the transport and injection of holes especially when the Al composition in the AlGaN EBL is high [14]. One multi-layer staircase hetero-structure was proposed for the $\mathrm{p}$-type region of DUV LEDs. Moreover, the materials of n-AlGaN layer, quantum barrier (QB), and EBL were also investigated to probe into the capability of carrier confinement of DUV LEDs in our previous research $[15,16]$. The simulation results show that these factors are all important to the output performance, while the cross-relation among these factors is complicated which needs further thorough exploration. In this study, a systematic investigation of AlGaN DUV LED structures is conducted numerically with a finite element approach, APSYS [17], to pursue the goal of high-performance structural designs. Specifically, influences of n-AlGaN layer, QB, and EBL on the optical performance of DUV LEDs are systematically explored. Furthermore, the physical origins such as the carrier transport, carrier confinement, and interband transitions of the relevant characterization are analyzed in detail.

\section{Device Structure and Parameters}

The DUV LED structure referred to the literature published by Yan et al. [18] is used as a reference, which has a peak emission wavelength of $284.5 \mathrm{~nm}$ at $60 \mathrm{~mA}$. The LED is composed of 3- $\mu$ m-thick $n-\mathrm{Al}_{0.6} \mathrm{Ga}_{0.4} \mathrm{~N}$ layer (n-doping $=4 \times 10^{18} \mathrm{~cm}^{-3}$ ), five pairs of undoped $\mathrm{QW}-\mathrm{Al}_{0.4} \mathrm{Ga}_{0.6} \mathrm{~N} / \mathrm{QB}-\mathrm{Al}_{0.5} \mathrm{Ga}_{0.5} \mathrm{~N}$ (thickness: $3 \mathrm{~nm} / 12 \mathrm{~nm}$ ) active region, 20-nmthick p- $\mathrm{Al}_{0.65} \mathrm{Ga}_{0.35} \mathrm{~N}$ EBL ( $\mathrm{p}$-doping $=2 \times 10^{19} \mathrm{~cm}^{-3}$ ), 50-nm-thick $\mathrm{p}-\mathrm{Al}_{0.5} \mathrm{Ga}_{0.5} \mathrm{~N}$ interlayer layer ( $\mathrm{p}$-doping $\left.=2 \times 10^{19} \mathrm{~cm}^{-3}\right)$, and 120-nm-thick $\mathrm{p}$-GaN contact layer ( $\mathrm{p}$-doping $=1$ $\times 10^{19} \mathrm{~cm}^{-3}$ ). The doping densities present dopant concentration. The device geometry is with a square shape of $400 \times 400 \mu \mathrm{m}^{2}$. The curve-fitting procedure of reference LED, in which relevant free parameters are fine-tuning in the simulation so that the simulated output power-current and current-voltage characteristics are best fitted to those obtained from experimental measurements, was conducted to calibrate the free parameters used in the simulation. In this study, Shockley-Read-Hall (SRH) lifetime, Auger coefficient, light extraction efficiency, and degree of electric polarization are determined to be $10 \mathrm{~ns}, 5 \times$ $10^{-30} \mathrm{~cm}^{6} / \mathrm{s}, 15 \%$, and $50 \%$, respectively, which are within the reasonable scope of these parameters in the published literature $[19,20]$. The feature of curve-fitting process and the material parameters used in the simulation can be found in [21].

The consequent research is based on the reference LED structure and the relevant material parameters. The large potential barrier of the valence band of heterojunction may obstruct transport and injection of hole especially when the Al composition in EBL is high. Since the Al composition in EBL is one of the key factors of this study, the DUV LED structure is modified to contain three p-type interlayers, in which the $\mathrm{Al}$ compositions are one, two, and three-quarters of that of EBL, in order to create a staircase band structure to enhance hole injection [14]. The total thickness of p-AlGaN interlayers is therefore increased from $50 \mathrm{~nm}$ of the reference structure to $120 \mathrm{~nm}(40+40+40 \mathrm{~nm})$ of the modified structure utilized in this study. Note that the thickness of $\mathrm{p}-\mathrm{GaN}$ contact layer is decreased accordingly in order to keep the total thickness of the DUV LED device unchanged. The schematic diagram of the DUV LED structure under study is depicted in Figure 1 for better reference, in which $\mathrm{x}, \mathrm{y}$, and $\mathrm{z}$ are the material parameters explored in this work. 


\begin{tabular}{|c|c|}
\hline \multicolumn{2}{|l|}{ ale } \\
\hline $\mathrm{p}-\mathrm{GaN}$ & {$[\mathrm{Mg}]=1 \times 10^{19} \mathrm{~cm}^{-3} \quad 50 \mathrm{~nm}$} \\
\hline p-Al $l_{(1 / 4 x<)} \mathrm{GaN}$ & {$[\mathrm{Mg}]=2 \times 10^{19} \mathrm{~cm}^{-3} \quad 40 \mathrm{~nm}$} \\
\hline $\mathrm{p}-\mathrm{Al}_{(2 / 4 x \not)} \mathrm{GaN}$ & {$[\mathrm{Mg}]=2 \times 10^{19} \mathrm{~cm}^{-3} \quad 40 \mathrm{~nm}$} \\
\hline p- $\mathrm{Al}_{(3 / 4 \times x)} \mathrm{GaN}$ & {$[\mathrm{Mg}]=2 \times 10^{19} \mathrm{~cm}^{-3} \quad 40 \mathrm{~nm}$} \\
\hline p- $\mathrm{Al}_{z} \mathrm{GaN}$ & $\begin{array}{l}\text { EBL } \\
{[\mathrm{Mg}]=2 \times 10^{19} \mathrm{~cm}^{-3} \quad 20 \mathrm{~nm}}\end{array}$ \\
\hline $\mathrm{AlGaN} / \mathrm{Aly}$ & $\begin{array}{l}\text { 5-pair MQWs } \\
\text { jaN } \quad(3 \mathrm{~nm} / 12 \mathrm{~nm})\end{array}$ \\
\hline $\mathrm{n}-\mathrm{Al}_{\mathrm{x}} \mathrm{GaN}$ & {$[\mathrm{Si}]=4 \times 10^{18} \mathrm{~cm}^{-3} \quad 1.5 \mu \mathrm{m}$} \\
\hline $\mathrm{n}-\mathrm{Al}_{\mathrm{x}} \mathrm{GaN}$ & {$[\mathrm{Si}]=4 \times 10^{18} \mathrm{~cm}^{-3} \quad 1.5 \mu \mathrm{m}$} \\
\hline
\end{tabular}

Figure 1. Schematic diagram of the deep-ultraviolet (DUV) light-emitting diode (LED) structure under study.

\section{Results and Analyses}

\subsection{The $A l_{0.4} G a_{0.6} \mathrm{~N} Q W s$}

The DUV LED structures with $\mathrm{Al}_{0.4} \mathrm{Ga}_{0.6} \mathrm{~N}$ QWs are first simulated to explore the impacts of structural design on LED performance, in which the peak emission wavelength of the studied LED structure with $\mathrm{Al}_{0.5} \mathrm{Ga}_{0.5} \mathrm{~N}$ QBs are $284.5 \mathrm{~nm}$ at $60 \mathrm{~mA}$. The emission spectrum is appropriately adjusted in the modified QW structure when the $\mathrm{Al}$ composition in QBs varies in the subsequent study.

\subsubsection{With $\mathrm{n}-\mathrm{Al}_{0.6} \mathrm{Ga}_{0.4} \mathrm{~N}$ Layer}

This section presents simulation results of DUV LED structures with $\mathrm{Al}_{0.4} \mathrm{Ga}_{0.6} \mathrm{~N}$ QWs and $\mathrm{n}-\mathrm{Al}_{0.6} \mathrm{Ga}_{0.4} \mathrm{~N}$ layer. Figure 2 depicts light output power and operation voltage as functions of $\mathrm{Al}$ composition in QBs when the DUV LED structures are with various $\mathrm{Al}$ compositions of EBL. As shown in Figure 2a, the output power increases with increasing $\mathrm{Al}$ composition in QBs when the $\mathrm{Al}$ composition in EBL is 0.65 , while the output power decreases with increasing $\mathrm{Al}$ composition in QBs in most situations when the $\mathrm{Al}$ compositions of EBL are 0.75 and 0.80. As for the DUV LEDs with an EBL of medium Al composition (e.g., $\mathrm{Al}_{\mathrm{EBL}}: 0.70$ ), the $\mathrm{Al}$ composition in QBs affects the LED performance in a more complicated way. Namely, the output power first remains steady, then decreases, and finally increases when the $\mathrm{Al}$ composition in QBs increases from 0.50 to 0.62 , while the variation of output power shrinks in comparison with the former LED structures with three kinds of EBL. Figure $2 b$ shows that the operation voltage of DUV LED increases with increasing $\mathrm{Al}$ composition in EBL; nevertheless, the variation in operation voltage is negligible when the Al composition in QBs varies. Note that, for the DUV LED structures under study, an EBL with a higher Al composition also comes with a higher Al composition in the p-type interlayers. A large operation voltage is thus resulted owing to the high bandgap energy of p-type layers. Since the tendency of output power is quite complex, detailed analyses are required to explain the aforementioned physical characteristics of DUV LEDs. 

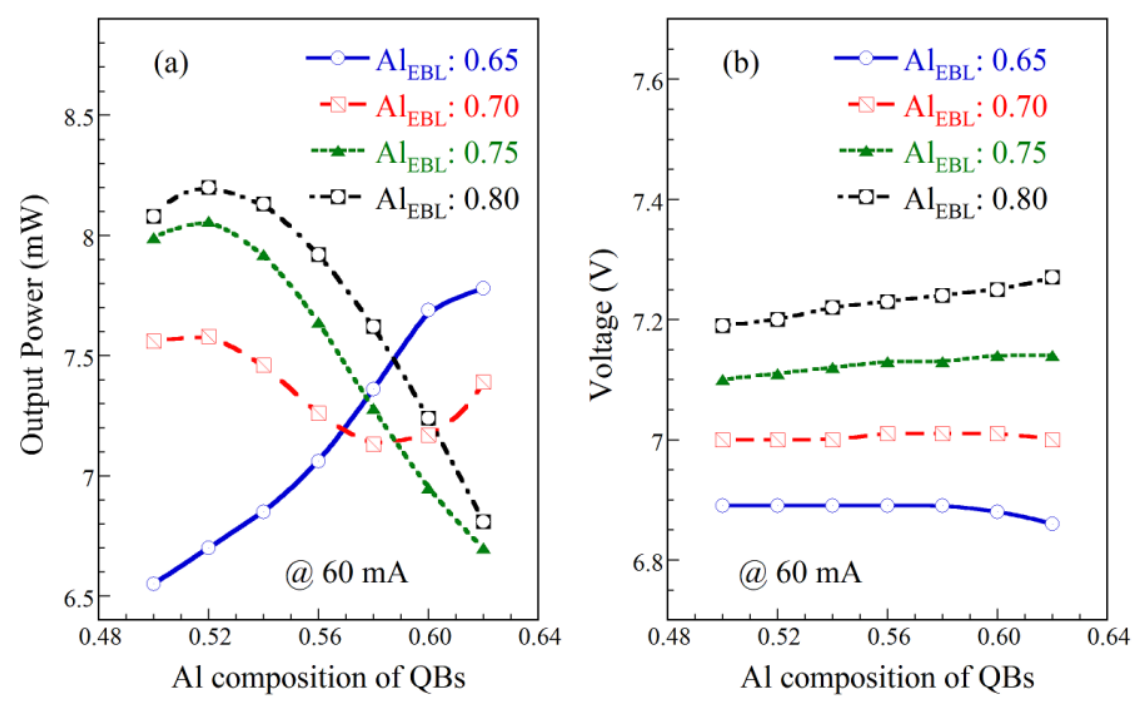

Figure 2. (a) Light output power and (b) operation voltage of DUV LEDs with various Al compositions of quantum barriers (QBs) and electron-blocking layer (EBL) at $60 \mathrm{~mA}$.

Figure 3 shows the conduction band diagram near the active region of the DUV LEDs with various $\mathrm{Al}$ compositions in $\mathrm{QBs}$ and $\mathrm{Al}_{0.65} \mathrm{Ga}_{0.35} \mathrm{~N}$ or $\mathrm{Al}_{0.8} \mathrm{Ga}_{0.2} \mathrm{~N}$ EBL. In comparison with $\mathrm{Al}_{0.65} \mathrm{Ga}_{0.35} \mathrm{~N}$ EBL, the $\mathrm{Al}_{0.8} \mathrm{Ga}_{0.2} \mathrm{~N}$ EBL possesses a much larger bandgap energy. The DUV LEDs with $\mathrm{Al}_{0.8} \mathrm{Ga}_{0.2} \mathrm{~N}$ EBL consequently require higher applied voltage to compensate the built-in potential and also to facilitate hole injection across a larger potential barrier of EBL. The higher conduction band edges of MQWs and n-AlGaN layer for DUV LEDs with $\mathrm{Al}_{0.8} \mathrm{Ga}_{0.2} \mathrm{~N}$ EBL shown in Figure 3 are therefore ascribed to the higher operation voltage. Moreover, as also shown in Figure 3, deformed and sloped band profiles appear owing to the massive polarization-induced surface charges located in heterojunction and the corresponding polarization field. In polar III-nitride materials, the polarization charges arise from the polarization difference between adjacent hetero-layers. The calculated sheet polarization charges located in the interface between the QW and QB are $\pm 2.59 \times$ $10^{16}, \pm 4.25 \times 10^{16}$ and $\pm 6.00 \times 10^{16} \mathrm{~m}^{-2}$ for the DUV LED structures with $\mathrm{Al}_{0.5} \mathrm{Ga}_{0.5} \mathrm{~N}$, $\mathrm{Al}_{0.56} \mathrm{Ga}_{0.44} \mathrm{~N}$, and $\mathrm{Al}_{0.62} \mathrm{Ga}_{0.38} \mathrm{~N} \mathrm{QBs}$, respectively. Note that a screening ratio of $50 \%$ as mentioned formerly has been included in above calculation of polarization charges. In the simulation, the polarization charges are computed in conjunction with other space charges self-consistently to estimate the total built-in electric field. When the DUV LED structure is with higher $\mathrm{Al}$ composition in QBs, not only the discrepancy of bandgap energy between the QW and QB increases, but the total polarization enlarges as well. The deeper but more sloped QWs cause opposite effects in carrier confinement. Moreover, a smaller energy band offset exists in the hetero-interface of the last QB and EBL, which causes slighter polarization even for high Al-composition QBs. The aforementioned multiple factors affect the carrier transportation and recombination mechanisms of DUV LEDs jointly, which makes the prediction of output performance difficult. For example, utilizing higher $\mathrm{Al}$ composition in EBL is generally believed to be beneficial for the confinement of electrons due to the high bandgap energy of EBL. As shown in the upper two sub-figures of Figure 3, two different EBLs were employed for DUV LEDs with the same 0.50-Al-composition QBs. With a higher 0.80-Al-composition EBL, a larger potential barrier indeed provides better confinement capability for electrons in comparison with the counterpart with lower 0.65-Al-composition EBL. However, for the structures with 0.62-Al-composition QBs, as shown in the lower two sub-figures of Figure 3, the effective potential barrier height of EBL, defined as the potential difference between the quasi-Fermi level of the last $\mathrm{QB}$ and maximum conduction band edge of EBL, shrinks ( $397 \mathrm{meV}$ vs. $350 \mathrm{meV}$ ) when the $\mathrm{Al}$ composition in EBL increases from 0.65 to 0.80 . Note that the maximum conduction edge of MQW active region is almost identical to that of EBL when the EBL is with 0.65 or 0.80 
$\mathrm{Al}$ composition. Thus, EBL with higher Al composition may lead to a worse capability of electron confinement for the DUV LED with 0.62-Al-composition QBs.

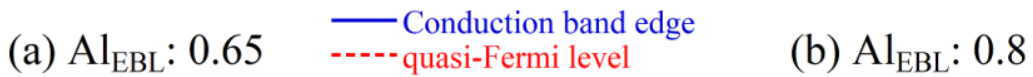
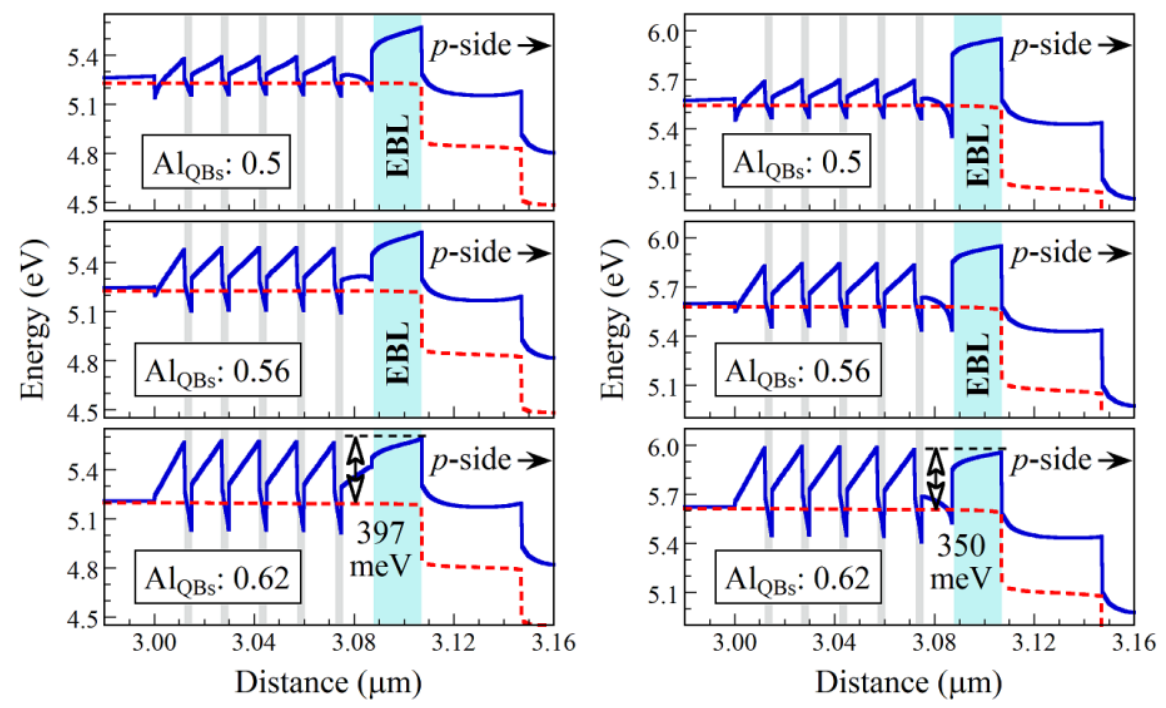

Figure 3. Conduction band diagram near active region of the DUV LEDs with various Al compositions of QBs and (a) $\mathrm{Al}_{0.65} \mathrm{Ga}_{0.35} \mathrm{~N}$ EBL and (b) $\mathrm{Al}_{0.8} \mathrm{Ga}_{0.2} \mathrm{~N}$ EBL respectively at $60 \mathrm{~mA}$.

In order to evaluate the capability of electron confinement, the normalized electron current density of DUV LEDs with various $\mathrm{Al}$ compositions of $\mathrm{QBs}$ and $\mathrm{Al}_{0.65} \mathrm{Ga}_{0.35} \mathrm{~N}$ or $\mathrm{Al}_{0.8} \mathrm{Ga}_{0.2} \mathrm{~N}$ EBL are depicted in Figure 4. As shown in Figure 4a, for the DUV LEDs with $\mathrm{Al}_{0.65} \mathrm{Ga}_{0.35} \mathrm{~N}$ EBL, the proportion of electron current leakage is originally $37.4 \%$ for the condition of $\mathrm{Al}_{\mathrm{QBs}}: 0.50$, and then slightly increases to $41.6 \%$ for $\mathrm{Al}_{\mathrm{QBs}}: 0.56$, and finally reduces to a much small value of $7.1 \%$ for $\mathrm{Al}_{\mathrm{QBs}}: 0.62$. Since the electron current leaking out of the active region is as large as $41.6 \%$ for the severest case, the capability of electron confinement is the very important issue influencing the performance of DUV LEDs. As for the DUV LEDs with $\mathrm{Al}_{0.8} \mathrm{Ga}_{0.2} \mathrm{~N}$ EBL, the relatively slight electron current leakage increases with increasing $\mathrm{Al}$ composition in QBs. Note that the aforementioned situation of electron current leakage is closely related to the output performance shown in Figure 2a, which proves the significance of electron confinement capability to the performance of DUV LEDs. Another inspiring finding of Figure 4 is that the capability of electron confinement may enhance with appropriate structural design by fine-tuning the critical structure parameters.

Figure 5 shows carrier concentration and SRH recombination of the DUV LEDs with $\mathrm{Al}_{0.65} \mathrm{Ga}_{0.35} \mathrm{~N}$ EBL and $\mathrm{Al}_{0.5} \mathrm{Ga}_{0.5} \mathrm{~N}$ or $\mathrm{Al}_{0.56} \mathrm{Ga}_{0.44} \mathrm{~N}$ QBs. When DUV LED is with QBs of relatively low $\mathrm{Al}$ composition (e.g., $\mathrm{Al}_{\mathrm{QBs}}$ : 0.50), some carriers spill over from the very shallow QWs which will generate extra SRH recombination in QBs, which is indicated with a dashed rectangular-shape line in Figure 5a. The integrated SRH recombination for DUV LEDs with $\mathrm{Al}_{0.65} \mathrm{Ga}_{0.35} \mathrm{~N}$ EBL and $\mathrm{Al}_{0.5} \mathrm{Ga}_{0.5} \mathrm{~N}, \mathrm{Al}_{0.56} \mathrm{Ga}_{0.44} \mathrm{~N}$ or $\mathrm{Al}_{0.62} \mathrm{Ga}_{0.38} \mathrm{~N}$ QBs are $1.87 \times 10^{20}, 1.26 \times 10^{20}$, and $1.11 \times 10^{20} \mathrm{~cm}^{-2} \mathrm{~s}^{-1}$, respectively, in which the value of the structure with $\mathrm{Al}_{0.5} \mathrm{Ga}_{0.5} \mathrm{~N}$ QBs is $33 \%$ higher than that with $\mathrm{Al}_{0.56} \mathrm{Ga}_{0.44} \mathrm{~N}$ QBs and $41 \%$ higher than that with $\mathrm{Al}_{0.62} \mathrm{Ga}_{0.38} \mathrm{~N}$ QBs. The severer SRH recombination loss is presumably the reason why the DUV LED with $\mathrm{Al}_{0.65} \mathrm{Ga}_{0.35} \mathrm{~N}$ EBL and $\mathrm{Al}_{0.5} \mathrm{Ga}_{0.5} \mathrm{~N}$ QBs possesses a lower electron leakage current but an inferior light output power, in comparison with the counterpart with $\mathrm{Al}_{0.65} \mathrm{Ga}_{0.35} \mathrm{~N}$ EBL and $\mathrm{Al}_{0.56} \mathrm{Ga}_{0.44} \mathrm{~N}$ QBs, as shown in Figures 2a and 4a. Consequently, the SRH recombination markedly affects the output performance of DUV LEDs, especially when the $\mathrm{Al}$ composition in QBs is low. As shown in Figure 2a, the phenomenon that the output power increases initially with increasing $\mathrm{Al}$ composition of QBs when the $\mathrm{Al}$ composition of $\mathrm{EBL}$ is 0.75 or 0.80 should also result from 
the reduced SRH recombination. Note that, besides the aforementioned issues of carrier confinement and spillover arisen from QBs, the spatial separation of electron and hole wavefunctions in QWs also influences the interband transitions and output performance of DUV LEDs. As shown in the upper two sub-figures of Figure 5, it is obvious that the overlap of electron and hole concentrations of the LED with $\mathrm{Al}_{0.56} \mathrm{Ga}_{0.44} \mathrm{~N}$ QBs is much worse than that of the LED with $\mathrm{Al}_{0.5} \mathrm{Ga}_{0.5} \mathrm{~N}$ QBs. Under the circumstance, the efficiency of radiative recombination would be degraded even more with the severer influence of quantum-confined Stark effect (QCSE) [22,23]. The affected carriers, i.e., the carriers which would originally recombine radiatively, thus turn to recombine non-radiatively through SRH or Auger recombination or leak out of the active region as leakage current. Moreover, the energy band structure of the LED with $\mathrm{Al}_{0.56} \mathrm{Ga}_{0.44} \mathrm{~N}$ QBs suffers from more severe polarization effect. The recombination mechanism would be affected, and the proportion of interband transitions is therefore changed with the corresponding more sloped QWs. In view of the above analyses, the output performance of DUV LEDs has a complicated relation with the joint effect of the aforementioned critical issues.
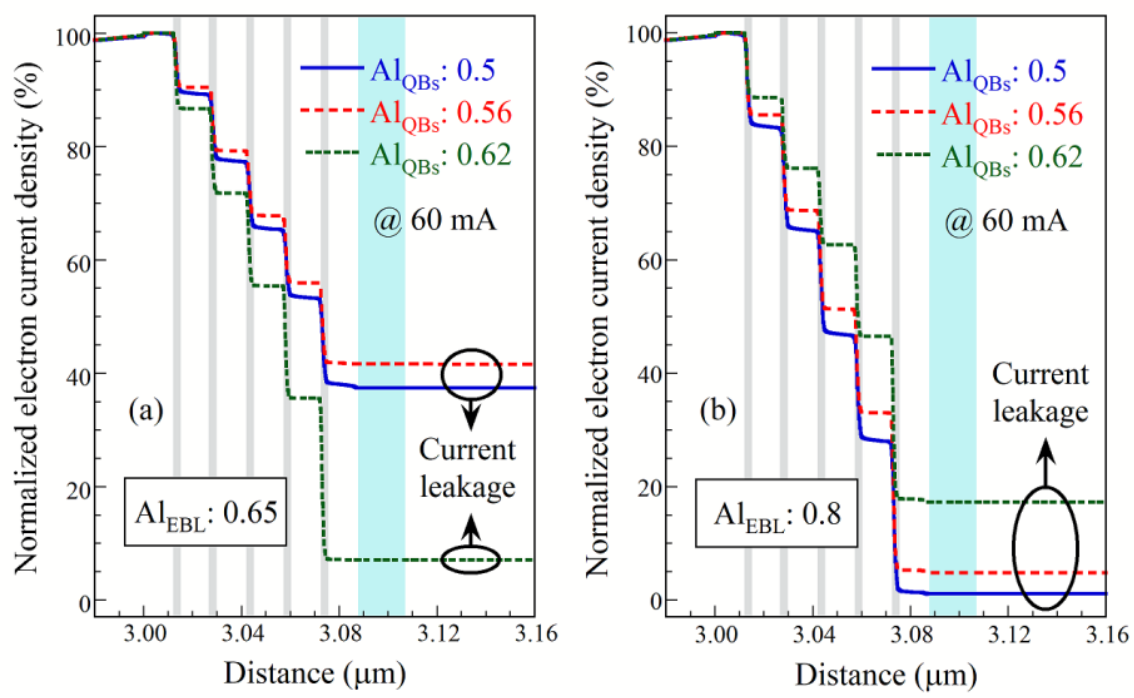

Figure 4. Normalized electron current density of the DUV LEDs with various $\mathrm{Al}$ compositions of QBs and (a) $\mathrm{Al}_{0.65} \mathrm{Ga}_{0.35} \mathrm{~N}$ EBL and (b) $\mathrm{Al}_{0.8} \mathrm{Ga}_{0.2} \mathrm{~N}$ EBL at $60 \mathrm{~mA}$.

In summary, the influences of $\mathrm{Al}$ composition of $\mathrm{QBs}$ and $\mathrm{EBL}$ on the output performance of DUV LEDs with $\mathrm{Al}_{0.4} \mathrm{Ga}_{0.6} \mathrm{~N}$ QWs and $\mathrm{n}-\mathrm{Al}_{0.6} \mathrm{Ga}_{0.4} \mathrm{~N}$ layer are systematically investigated in Section 3.1.1. Increasing the $\mathrm{Al}$ composition of $\mathrm{QBs}$ not only increases the depth of QWs, but also increases the polarization-induced electric field across the QWs and decreases the discontinuity of the energy band in the last-QB/EBL interface. Similarly, increasing the $\mathrm{Al}$ composition of EBL not only increases the potential barrier of EBL in conduction band, but also increases the potential barrier in valence band and increases the polarization field across the EBL. Note that an increase of operation voltage is observed with the increase of $\mathrm{Al}$ composition of EBL. The above-mentioned multiple factors affect the DUV LEDs jointly. A thorough analysis of the entire LED device is therefore required. Simulation results show that the output power increases with increasing $\mathrm{Al}$ composition of QBs when the DUV LEDs are with $\mathrm{Al}_{0.65} \mathrm{Ga}_{0.35} \mathrm{~N}$ EBL, whereas the output power substantially decreases with increasing $\mathrm{Al}$ composition of QBs when the DUV LEDs are with $\mathrm{Al}_{0.75} \mathrm{Ga}_{0.25} \mathrm{~N}$ or $\mathrm{Al}_{0.8} \mathrm{Ga}_{0.2} \mathrm{~N}$ EBL. As for the DUV LEDs with $\mathrm{Al}_{0.7} \mathrm{Ga}_{0.3} \mathrm{~N}$ EBL, as shown in Figure 2a, the output power decreases first, which is similar to the DUV LEDs with $\mathrm{Al}_{0.75} \mathrm{Ga}_{0.25} \mathrm{~N}$ or $\mathrm{Al}_{0.8} \mathrm{Ga}_{0.2} \mathrm{~N}$ EBL , and then increases with increasing $\mathrm{Al}$ composition of QBs, which is similar to the DUV LEDs with $\mathrm{Al}_{0.65} \mathrm{Ga}_{0.35} \mathrm{~N}$ EBL. Although the characteristics of DUV LED are affected by the multiple factors mentioned above, the capability of carrier confinement is a crucial indication for the evaluation of output performance. 
The electron current leakages for the DUV LEDs with $\mathrm{Al}_{0.7} \mathrm{Ga}_{0.3} \mathrm{~N}$ EBL, and $\mathrm{Al}_{0.5} \mathrm{Ga}_{0.5} \mathrm{~N}$, $\mathrm{Al}_{0.58} \mathrm{Ga}_{0.42} \mathrm{~N}$, and $\mathrm{Al}_{0.62} \mathrm{Ga}_{0.38} \mathrm{~N}$ QBs are $15.8 \%, 34.6 \%$, and $28.6 \%$, respectively, which clarify the tendency of output power shown in Figure 2a. The variation of output power for the DUV LED with $\mathrm{Al}_{0.7} \mathrm{Ga}_{0.3} \mathrm{~N}$ EBL is much smaller than the other counterparts with the variation of QBs due to the more pronounced trade-off among the multiple impact factors.
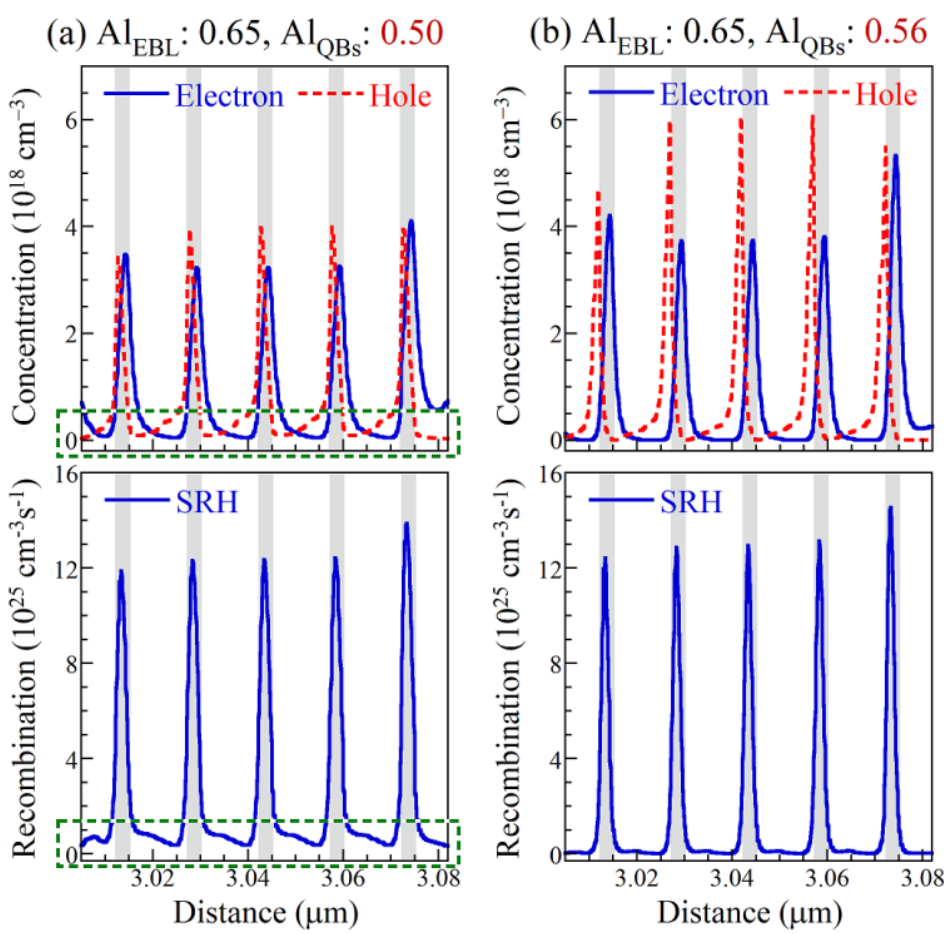

Figure 5. Carrier concentration and Shockley-Read-Hall (SRH) recombination of the DUV LEDs with $\mathrm{Al}_{0.65} \mathrm{Ga}_{0.35} \mathrm{~N}$ EBL and (a) $\mathrm{Al}_{0.5} \mathrm{Ga}_{0.5} \mathrm{~N}$ QBs and (b) $\mathrm{Al}_{0.56} \mathrm{Ga}_{0.44} \mathrm{~N}$ QBs respectively at $60 \mathrm{~mA}$.

\subsubsection{With $\mathrm{n}-\mathrm{Al}_{0.5} \mathrm{Ga}_{0.5} \mathrm{~N}$ layer and $\mathrm{n}-\mathrm{Al}_{0.7} \mathrm{Ga}_{0.3} \mathrm{~N}$ Layer}

The DUV LED structures with $\mathrm{Al}_{0.4} \mathrm{Ga}_{0.6} \mathrm{~N}$ QWs and distinct $\mathrm{n}$-AlGaN layers are also explored in this study. Figure 6 shows the wall-plug efficiency (WPE) of DUV LEDs with $\mathrm{Al}_{0.4} \mathrm{Ga}_{0.6} \mathrm{~N}$ QWs and $\mathrm{n}-\mathrm{Al}_{0.5} \mathrm{Ga}_{0.5} \mathrm{~N}, \mathrm{n}-\mathrm{Al}_{0.6} \mathrm{Ga}_{0.4} \mathrm{~N}$, or $\mathrm{n}-\mathrm{Al}_{0.7} \mathrm{Ga}_{0.3} \mathrm{~N}$ layer at $60 \mathrm{~mA}$. The WPE is relevant to both optical and electrical performance of DUV LEDs. The WPE of DUV LEDs with $\mathrm{n}-\mathrm{Al}_{0.6} \mathrm{Ga}_{0.4} \mathrm{~N}$ layer is also depicted in Figure 6 for comparison purposes. The study shows that the $\mathrm{Al}$ composition in $\mathrm{n}-\mathrm{AlGaN}$ layer indeed plays an important role in influencing the output performance of DUV LEDs; namely, the WPE varies substantially with distinct n-AlGaN layers. Specifically, in the majority of cases, the lower Al composition in n-AlGaN layer is adopted, the higher WPE will be achieved. Moreover, when the DUV LED structures are with lower $\mathrm{Al}$ composition in n-AlGaN layer, the variation of WPE is relatively small with the changes of QB and EBL materials. The higher WPE for the DUV LEDs with lower $\mathrm{Al}$ composition in n-AlGaN layer attributes partially to the reduced operation voltage in accordance with the smaller bandgap energy of n-type layer. In addition to this, more physical mechanisms, such as the different energy band profiles and their corresponding carrier confinement capability, are required to explain the aforementioned DUV LED characteristics shown in Figure 6. Furthermore, several desirable DUV LED structures with optimum WPE are summarized in Table 1 for better reference. 


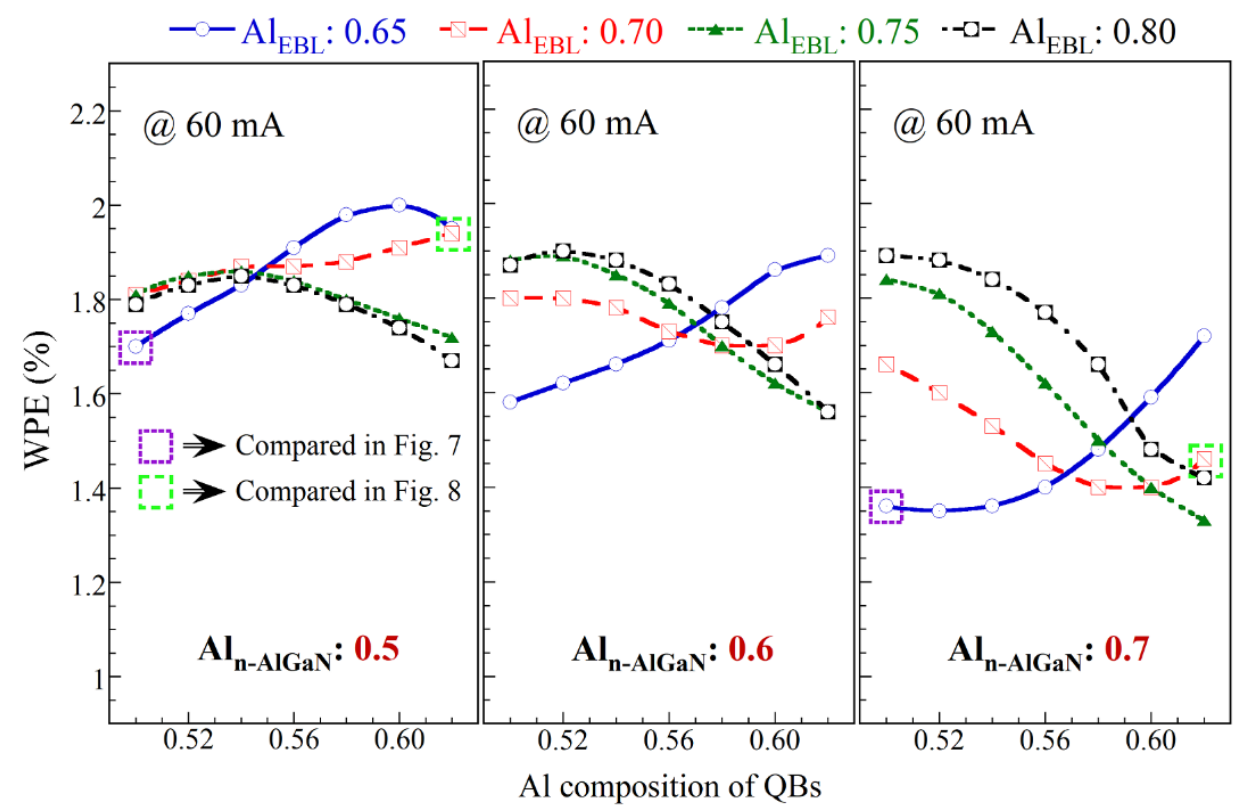

Figure 6. Wall-plug efficiency (WPE) of the DUV LEDs with $\mathrm{Al}_{0.4} \mathrm{Ga}_{0.6} \mathrm{~N} \mathrm{QWs}$ and $\mathrm{n}-\mathrm{Al}_{0.5} \mathrm{Ga}_{0.5} \mathrm{~N}$, $\mathrm{n}-\mathrm{Al}_{0.6} \mathrm{Ga}_{0.4} \mathrm{~N}$, or $\mathrm{n}-\mathrm{Al}_{0.7} \mathrm{Ga}_{0.3} \mathrm{~N}$ layer at $60 \mathrm{~mA}$.

Table 1. Several desirable DUV LED structures with optimum WPE for $\mathrm{Al}_{0.4} \mathrm{Ga}_{0.6} \mathrm{~N}$ QWs.

\begin{tabular}{cccccc}
\hline \multicolumn{3}{c}{$\mathbf{A l}_{\mathbf{0 . 4}} \mathbf{G a}_{\mathbf{0 . 6}} \mathbf{N} \mathbf{Q W s}$} & \multicolumn{3}{c}{$@ \mathbf{6 0} \mathbf{~ m A}$} \\
\hline $\mathbf{A l}_{\text {n-AlGaN }}$ & $\mathbf{A l}_{\text {EBL }}$ & $\mathbf{A l}_{\mathbf{Q B s}}$ & Power $(\mathbf{m W})$ & Voltage (V) & WPE (\%) \\
\hline 0.50 & 0.65 & 0.58 & 7.99 & 6.73 & 1.98 \\
0.50 & 0.65 & 0.60 & 8.04 & 6.71 & 2.00 \\
0.50 & 0.65 & 0.62 & 7.83 & 6.68 & 1.95 \\
0.50 & 0.70 & 0.60 & 7.85 & 6.85 & 1.91 \\
0.50 & 0.70 & 0.62 & 7.96 & 6.83 & 1.94 \\
0.60 & 0.80 & 0.52 & 8.20 & 7.20 & 1.90 \\
\hline
\end{tabular}

Figure 7 shows the energy band diagram and normalized current density of DUV LEDs with $\mathrm{Al}_{0.5} \mathrm{Ga}_{0.5} \mathrm{~N}$ QBs, $\mathrm{Al}_{0.65} \mathrm{Ga}_{0.35} \mathrm{~N}$ EBL, and $\mathrm{n}-\mathrm{Al}_{0.5} \mathrm{Ga}_{0.5} \mathrm{~N}$ or $\mathrm{n}-\mathrm{Al}_{0.7} \mathrm{Ga}_{0.3} \mathrm{~N}$ layer. In comparison with the DUV LED with $\mathrm{n}-\mathrm{Al}_{0.5} \mathrm{Ga}_{0.5} \mathrm{~N}$ layer, employment of $\mathrm{n}-\mathrm{Al}_{0.7} \mathrm{Ga}_{0.3} \mathrm{~N}$ layer not only enlarges the bandgap energy but also modifies the energy band profile of the MQW active region. Under the circumstances, even though these two LED structures possess identical QB and EBL, the effective potential barrier height of EBL for the structure with $\mathrm{n}-\mathrm{Al}_{0.7} \mathrm{Gaa}_{0.3} \mathrm{~N}$ layer is relatively lower than that of the counterpart structure with $\mathrm{n}-\mathrm{Al}_{0.5} \mathrm{Ga}_{0.5} \mathrm{~N}$ layer, which leads to a much severer electron current leakage as shown in the lower two sub-figures of Figure 7. Moreover, as shown in Figure $7 \mathrm{~b}$, the much higher potential barrier in the valence band of the interface between the n-AlGaN layer and first QB can provide excellent confinement capability preventing holes escaping the MQW active region. The relevant structure therefore exhibits no hole leakage current, as also shown in Figure $7 \mathrm{~b}$. Note that most of the DUV LED structures studied reveal much severer electron current leakage accompanying slight or negligible hole current leakage. The issue of electron confinement thus plays a much more important role in influencing the output performance of DUV LEDs. 
(a) $\mathrm{Al}_{\mathrm{n}-\mathrm{AlGaN}}: \mathbf{0 . 5}, \mathrm{Al}_{\mathrm{EBL}}: 0.65, \mathrm{Al}_{\mathrm{QBs}}: 0.50$

(b) $\mathrm{Al}_{\mathrm{n}-\mathrm{AlGaN}}: 0.7, \mathrm{Al}_{\mathrm{EBL}}: 0.65, \mathrm{Al}_{\mathrm{QBs}}: 0.50$
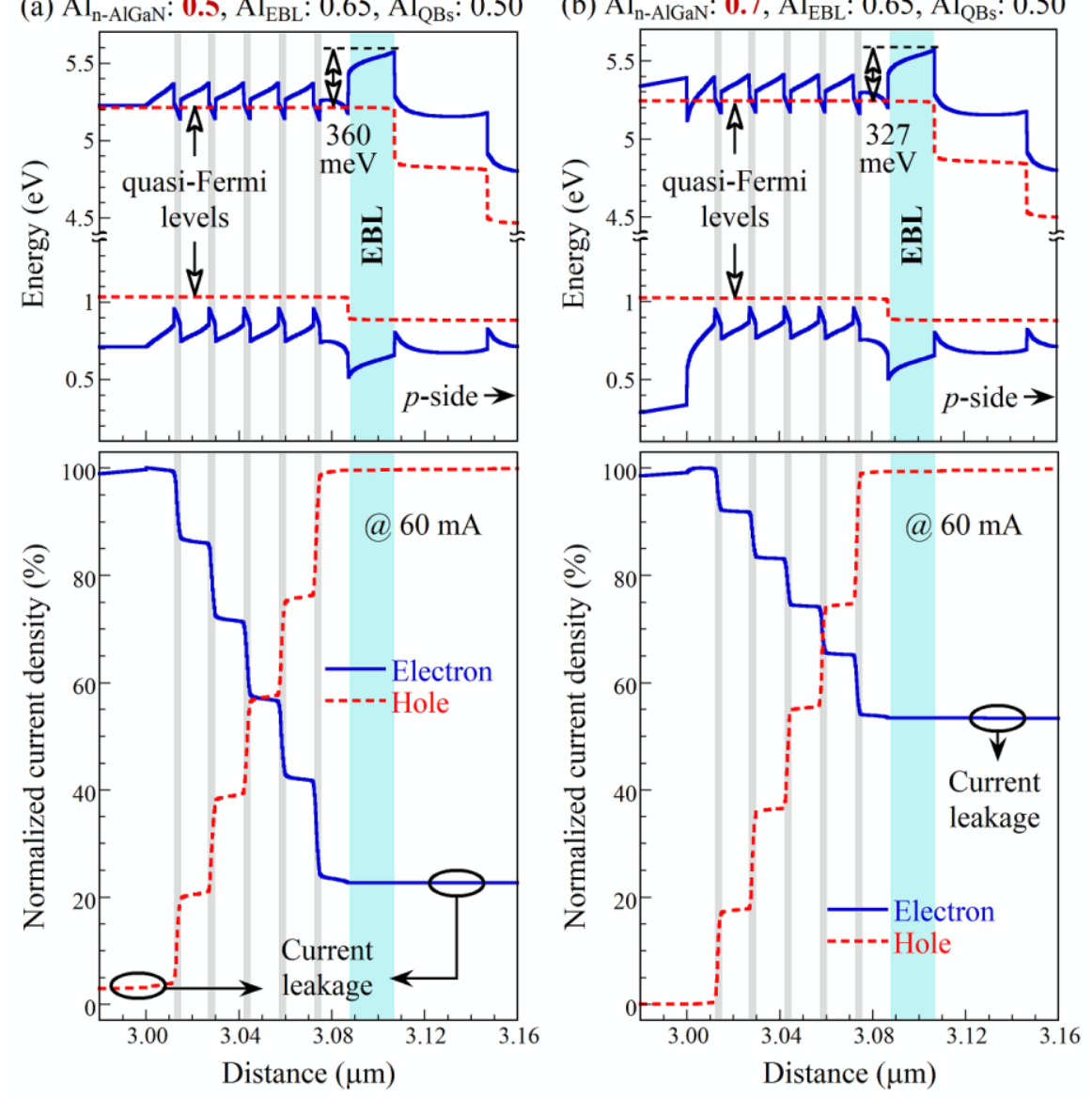

Figure 7. Energy band diagram and normalized current density of the DUV LED structures with $\mathrm{Al}_{0.5} \mathrm{Ga}_{0.5} \mathrm{~N}$ QBs, $\mathrm{Al}_{0.65} \mathrm{Ga}_{0.35} \mathrm{~N}$ EBL, and (a) $\mathrm{n}-\mathrm{Al}_{0.5} \mathrm{Ga}_{0.5} \mathrm{~N}$ layer or (b) $\mathrm{n}-\mathrm{Al}_{0.7} \mathrm{Ga}_{0.3} \mathrm{~N}$ layer at $60 \mathrm{~mA}$.

Figure 6 provides design curves for several different DUV LED structures, which can be beneficial for the researchers to design the LED structures operating in DUV spectral range with good LED performance. The distinct capabilities of carrier confinement under various DUV LED structures bring about different output performance as shown in Figure 6. For example, when the DUV LEDs are with $\mathrm{Al}_{0.62} \mathrm{Ga}_{0.38} \mathrm{~N}$ QBs and $\mathrm{Al}_{0.7} \mathrm{Ga}_{0.3} \mathrm{~N}$ EBL, employing a distinct $\mathrm{n}-\mathrm{AlGaN}$ layer leads to quite different performance in WPE as well. Figure 8 shows the energy band diagram and normalized current density of the DUV LED structures with $\mathrm{Al}_{0.62} \mathrm{Ga}_{0.38} \mathrm{~N}$ QBs, $\mathrm{Al}_{0.7} \mathrm{Ga}_{0.3} \mathrm{~N}$ EBL , and $\mathrm{n}-\mathrm{Al}_{0.5} \mathrm{Ga}_{0.5} \mathrm{~N}$ or $\mathrm{n}-\mathrm{Al}_{0.7} \mathrm{Ga}_{0.3} \mathrm{~N}$ layer. Similar to the analyses discussed previously, the capability of carrier confinement is quite different for these two new cases, which proves again the significance of appropriate usage of n-AlGaN layer. 
(a) $\mathrm{Al}_{\mathrm{n}-\mathrm{AlGaN}}: 0.5, \mathrm{Al}_{\mathrm{EBL}}: 0.70, \mathrm{Al}_{\mathrm{QBs}}: 0.62$

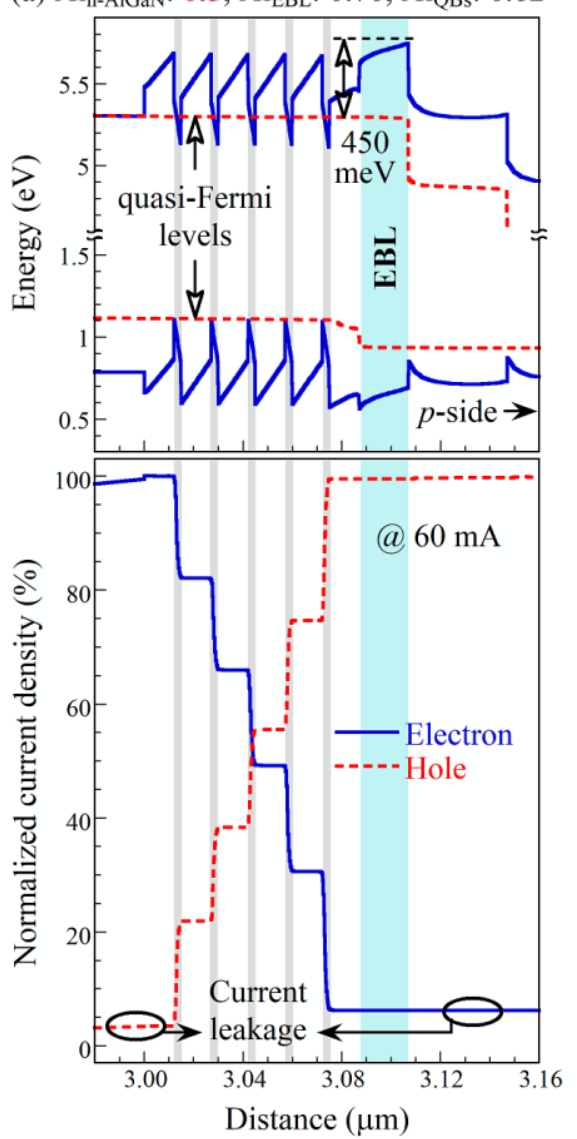

(b) $\mathrm{Al}_{\mathrm{n}-\mathrm{AlGaN}}: 0.7, \mathrm{Al}_{\mathrm{EBL}}: 0.70, \mathrm{Al}_{\mathrm{QBs}}: 0.62$

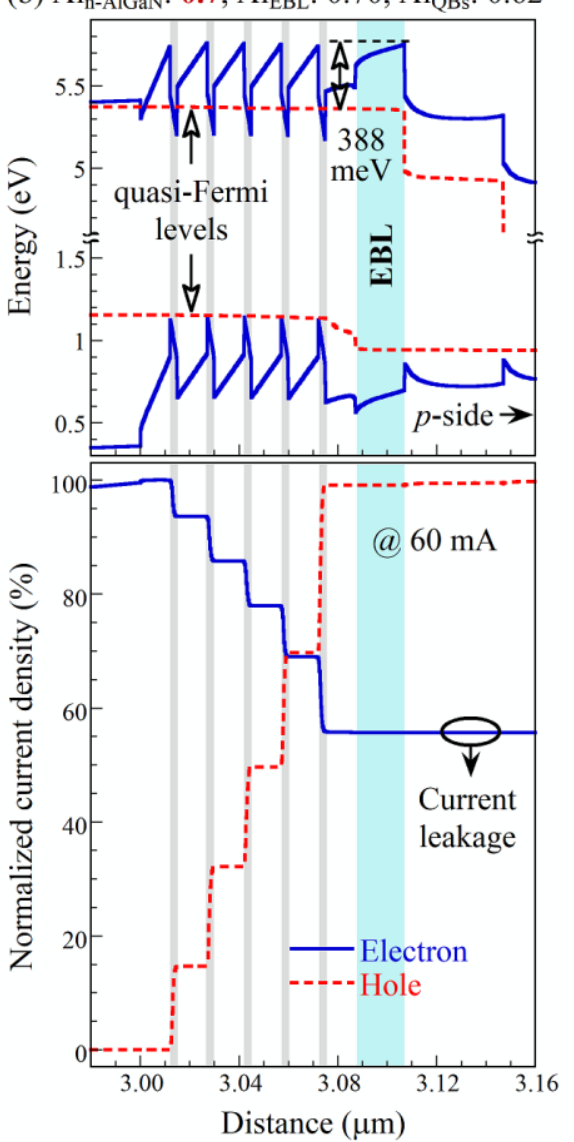

Figure 8. Energy band diagram and normalized current density of the DUV LED structures with $\mathrm{Al}_{0.62} \mathrm{Ga}_{0.38} \mathrm{~N}$ QBs, $\mathrm{Al}_{0.7} \mathrm{Ga}_{0.3} \mathrm{~N}$ EBL, and (a) $\mathrm{n}-\mathrm{Al}_{0.5} \mathrm{Ga}_{0.5} \mathrm{~N}$ layer or $(\mathbf{b}) \mathrm{n}-\mathrm{Al}_{0.7} \mathrm{Ga}_{0.3} \mathrm{~N}$ layer at $60 \mathrm{~mA}$.

\subsection{The $A l_{0.5} \mathrm{Ga}_{0.5} \mathrm{~N}$ and $A l_{0.6} \mathrm{Ga}_{0.4} \mathrm{~N} Q W \mathrm{Q}$}

The exploration of DUV LED structure with $\mathrm{Al}_{0.4} \mathrm{Ga}_{0.6} \mathrm{~N}$ QWs shows that the materials of $\mathrm{n}-\mathrm{AlGaN}$ layer, $\mathrm{QB}$, and EBL are critical factors in affecting the physical mechanisms of DUV LEDs. Specifically, when DUV LEDs are with different structure parameters, significant issues including capability of carrier confinement, polarization effect, and interband transitions will vary accordingly. Note that the above issues may influence each other reciprocally, i.e., if the DUV LED is with a distinct degree of polarization effect, the situation of carrier confinement and interband transition will be affected by the deformed energy band profile. The complicated joint effect arising from the above critical issues makes the output performance of DUV LEDs change accordingly.

In order to have a more complete study, the DUV LED structures with higher Alcomposition QWs are also simulated, which are with emission spectra in shorter spectral range when compared with the counterparts with $\mathrm{Al}_{0.4} \mathrm{Ga}_{0.6} \mathrm{~N}$ QWs. Figure 9 shows the WPE of DUV LED structures with $\mathrm{Al}_{0.5} \mathrm{Ga}_{0.5} \mathrm{~N}$ QWs and $\mathrm{Al}_{0.6} \mathrm{Ga}_{0.4} \mathrm{~N}$ QWs at $60 \mathrm{~mA}$. The peak emission wavelengths of the studied DUV LEDs with $\mathrm{Al}_{0.5} \mathrm{Ga}_{0.5} \mathrm{~N}$ QWs and $\mathrm{Al}_{0.6} \mathrm{Ga}_{0.4} \mathrm{~N}$ QWs are approximately $270 \mathrm{~nm}$ and $255 \mathrm{~nm}$, respectively, at $60 \mathrm{~mA}$. Comparing both Figures 6 and 9, the simulation results indicate that the tendencies in WPE with the variation of $\mathrm{n}-\mathrm{AlGaN}$ layer, $\mathrm{QB}$, and $\mathrm{EBL}$ are quite similar in the studied DUV LED structures with distinct QWs. However, the WPE of the DUV LEDs with either $\mathrm{Al}_{0.5} \mathrm{Ga}_{0.5} \mathrm{~N}$ QWs or $\mathrm{Al}_{0.6} \mathrm{Ga}_{0.4} \mathrm{~N}$ QWs is lower than that of the DUV LEDs with $\mathrm{Al}_{0.4} \mathrm{Ga}_{0.6} \mathrm{~N}$ QWs. The decrease in WPE for the DUV LEDs with high Al composition in the AlGaN QWs is due mainly to the relatively high bandgap energy of ternary AlGaN compound and the corresponding increased operation voltage. Moreover, the variation of WPE for the DUV LEDs with either $\mathrm{Al}_{0.5} \mathrm{Ga}_{0.5} \mathrm{~N}$ QWs or $\mathrm{Al}_{0.6} \mathrm{Ga}_{0.4} \mathrm{~N}$ QWs is larger than that of the DUV 
LEDs with $\mathrm{Al}_{0.4} \mathrm{Ga}_{0.6} \mathrm{~N}$ QWs under different situations of n-AlGaN layers, QBs, and EBLs. These simulation results show that appropriate structural design is even more important for the DUV LEDs operating in shorter emission wavelengths. Several desirable DUV LED structures with optimum WPE for $\mathrm{Al}_{0.5} \mathrm{Ga}_{0.5} \mathrm{~N}$ and $\mathrm{Al}_{0.6} \mathrm{Ga}_{0.4} \mathrm{~N} \mathrm{QWs}$ are summarized in Tables 2 and 3, respectively, for better reference.

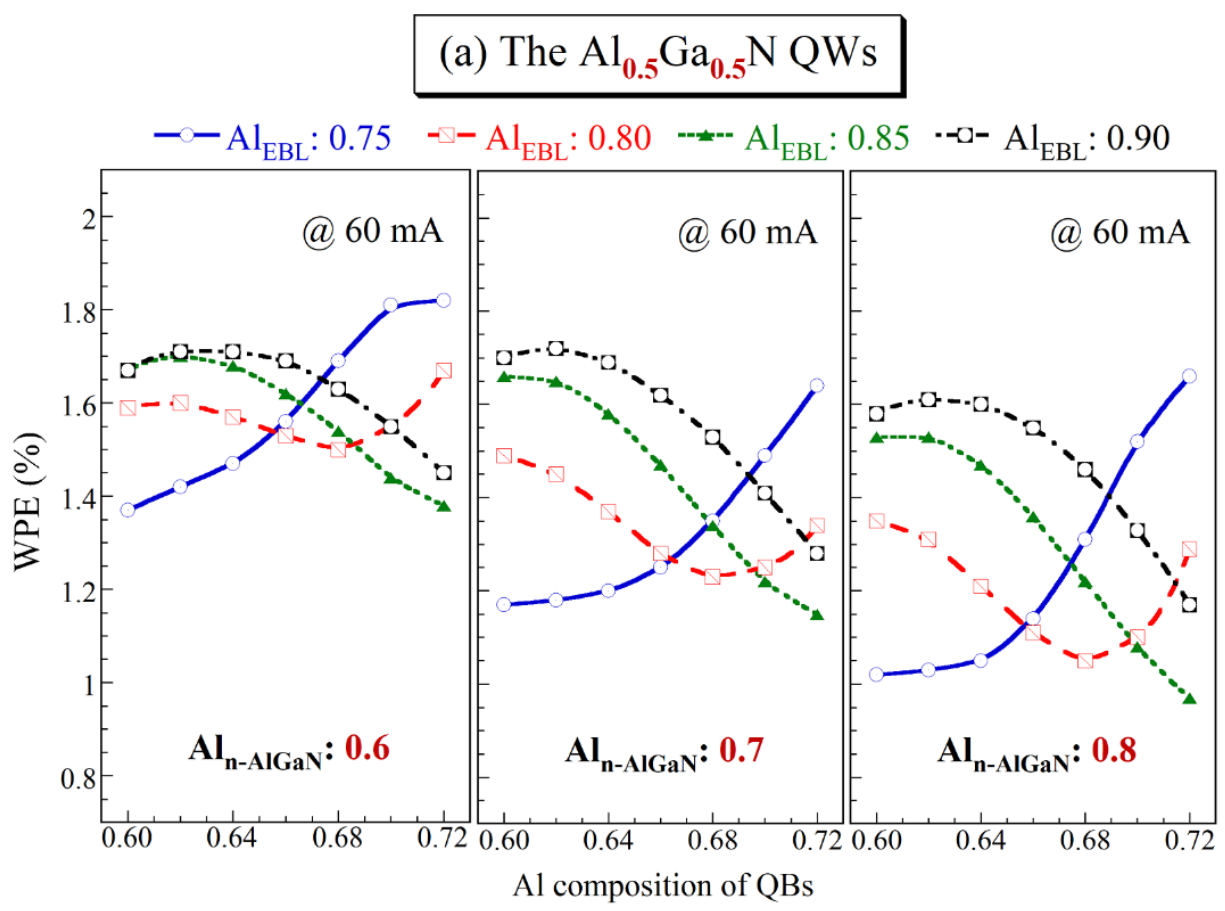

(b) The $\mathrm{Al}_{0.6} \mathrm{Ga}_{0.4} \mathrm{~N}$ QWs

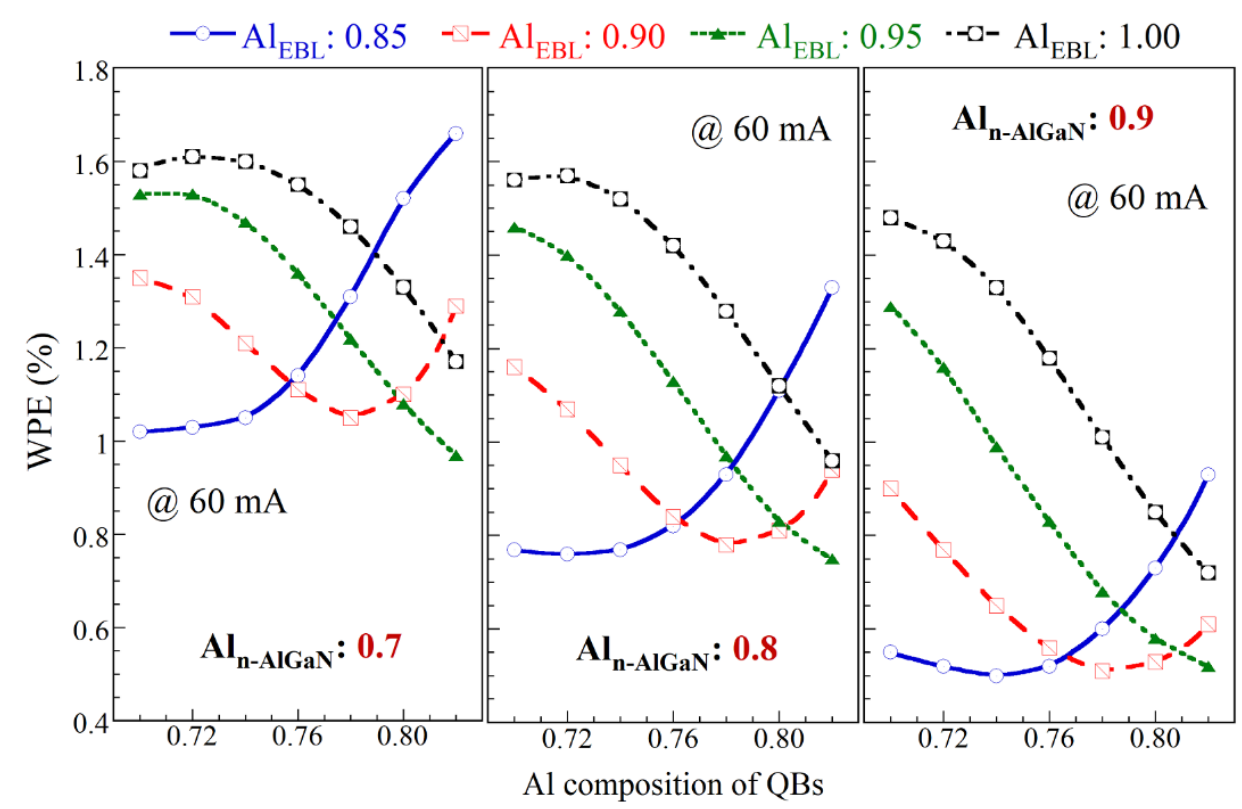

Figure 9. WPE of the DUV LED structures with (a) $\mathrm{Al}_{0.5} \mathrm{Ga}_{0.5} \mathrm{~N}$ QWs and (b) $\mathrm{Al}_{0.6} \mathrm{Ga}_{0.4} \mathrm{~N}$ QWs at $60 \mathrm{~mA}$. 
Table 2. Several desirable DUV LED structures with optimum WPE for $\mathrm{Al}_{0.5} \mathrm{Ga}_{0.5} \mathrm{~N}$ QWs.

\begin{tabular}{cccccc}
\hline \multicolumn{3}{c}{$\mathbf{A l}_{\mathbf{0 . 5}} \mathbf{G a}_{\mathbf{0 . 5}} \mathbf{N} \mathbf{Q W s}$} & \multicolumn{3}{c}{$@ \mathbf{6 0} \mathbf{~ m A}$} \\
\hline $\mathbf{A l}_{\mathbf{n}-\mathbf{A l G a N}}$ & $\mathbf{A l}_{\mathbf{E B L}}$ & $\mathbf{A l}_{\mathbf{Q B s}}$ & Power $(\mathbf{m W})$ & Voltage (V) & WPE (\%) \\
\hline 0.60 & 0.75 & 0.70 & 7.72 & 7.12 & 1.81 \\
0.60 & 0.75 & 0.72 & 7.77 & 7.10 & 1.82 \\
0.60 & 0.90 & 0.62 & 7.68 & 7.48 & 1.71 \\
0.60 & 0.90 & 0.64 & 7.70 & 7.49 & 1.71 \\
0.70 & 0.90 & 0.60 & 7.81 & 7.65 & 1.70 \\
0.70 & 0.90 & 0.62 & 7.91 & 7.66 & 1.72 \\
\hline
\end{tabular}

Table 3. Several desirable DUV LED structures with optimum WPE for $\mathrm{Al}_{0.6} \mathrm{Ga}_{0.4} \mathrm{~N}$ QWs.

\begin{tabular}{cccccc}
\hline & $\mathbf{A l}_{\mathbf{0 . 6}} \mathbf{G a}_{\mathbf{0 . 4}} \mathbf{N} \mathbf{Q W}$ & \multicolumn{3}{c}{$@ \mathbf{6 0} \mathbf{~ m A}$} \\
\hline $\mathbf{A l}_{\mathbf{n}-\mathbf{A l G a N}}$ & $\mathbf{A l}_{\mathbf{E B L}}$ & $\mathbf{A l}_{\mathbf{Q B s}}$ & Power $(\mathbf{m W})$ & Voltage (V) & WPE (\%) \\
\hline 0.70 & 0.85 & 0.82 & 7.55 & 7.58 & 1.66 \\
0.70 & 1.00 & 0.70 & 7.55 & 7.96 & 1.58 \\
0.70 & 1.00 & 0.72 & 7.72 & 7.98 & 1.61 \\
0.70 & 1.00 & 0.74 & 7.67 & 7.99 & 1.60 \\
0.80 & 1.00 & 0.70 & 7.69 & 8.20 & 1.56 \\
0.80 & 1.00 & 0.72 & 7.72 & 8.21 & 1.57 \\
\hline
\end{tabular}

\section{Conclusions}

This numerical study provides a systematic structural design to probe into the influences of $\mathrm{n}-\mathrm{AlGaN}$ layer, QB, and EBL on the output performance of AlGaN DUV LEDs in various emission spectral ranges. Specifically, the light output power, operation voltage, and WPE of the $\mathrm{Al}_{0.4} \mathrm{Ga}_{0.6} \mathrm{~N}$ LED structure that has a peak emission wavelength of 284.5 $\mathrm{nm}$ at $60 \mathrm{~mA}$ are investigated under the situations when the n-AlGaN layer has an $\mathrm{Al}$ composition of 0.4, 0.5, and 0.7, the AlGaN EBL has an Al composition of 0.65, 0.70, 0.75, and 0.80 , and the $\mathrm{AlGaN} \mathrm{QB}$ has an $\mathrm{Al}$ composition of 0.50 to 0.62 with an interval 0.02 . The energy band diagram, electron current density, carrier concentration, and SRH recombination of DUV LED structures are explored to study the physical mechanisms responsible for the optical and physical characteristics. Moreover, the WPEs of the $\mathrm{Al}_{0.5} \mathrm{Ga}_{0.5} \mathrm{~N}$ LED structure that has a peak emission wavelength of $270 \mathrm{~nm}$ at $60 \mathrm{~mA}$ are investigated under the situations when the $\mathrm{n}$-AlGaN layer has an $\mathrm{Al}$ composition of $0.6,0.7$, and 0.8 , the AlGaN EBL has an Al composition of 0.75, 0.80, 0.85, and 0.90, and the AlGaN QB has an $\mathrm{Al}$ composition of 0.60 to 0.72 with an interval 0.02 ; and the WPEs of the $\mathrm{Al}_{0.6} \mathrm{Ga}_{0.4} \mathrm{~N}$ LED structure that has a peak emission wavelength of $255 \mathrm{~nm}$ at $60 \mathrm{~mA}$ are investigated under the situations when the n-AlGaN layer has an Al composition of 0.7, 0.8, and 0.9, the AlGaN EBL has an Al composition of 0.85, 0.90, 0.95, and 1.00, and the AlGaN QB has an $\mathrm{Al}$ composition of 0.70 to 0.82 with an interval 0.02 . These design curves can be very useful for the researchers in developing the DUV LEDs with a peak emission wavelength ranging from $255 \mathrm{~nm}$ to $285 \mathrm{~nm}$. Similar analyses can apply to the study of the physical characteristics and optical performance of the DUV LEDs in other emission spectra as well.

The simulation results reveal that $\mathrm{n}-\mathrm{AlGaN}$ layer, $\mathrm{QB}$, and EBL are all critical factors in affecting the performance of DUV LEDs. Specifically, high-Al-composition QB and highAl-composition EBL utilized separately is found to be beneficial for the enhancement of carrier confinement, while the WPE may degrade dramatically if both high-Al-composition QB and high-Al-composition EBL are employed in the DUV LED structure simultaneously. Moreover, in most situations under study, the lower the Al composition in n-AlGaN layer, the higher WPE the LED will have. With distinct designs of epitaxial structure, the output performance of DUV LEDs could differ significantly, especially when the Al composition in QWs is relatively high, for example, the situation of $\mathrm{Al}_{0.6} \mathrm{Ga}_{0.4} \mathrm{~N} \mathrm{QWs}$. In summary, this study concludes that high-performance DUV LEDs can be achieved with appropriate structural design by fine-tuning the material parameters in n-AlGaN layer, QB, and EBL. 


\begin{abstract}
Author Contributions: Conceptualization, J.-Y.C., M.-F.H. and Y.-K.K.; methodology, J.-Y.C.; software, J.-Y.C.; validation, C.-Y.H., S.-C.L. and C.-C.W.; formal analysis, J.-Y.C., M.-F.H. and Y.-K.K.; investigation, J.-Y.C., C.-Y.H. and S.-C.L.; resources, Y.-K.K.; data curation, C.-Y.H., S.-C.L. and C.C.W.; writing — original draft preparation, J.-Y.C.; writing—review and editing, M.-F.H. and Y.-K.K.; funding acquisition, C.-C.W. and Y.-K.K. All authors have read and agreed to the published version of the manuscript.
\end{abstract}

Funding: This research was funded by the Ministry of Science and Technology (Taiwan), grant numbers MOST-105-2112-M-018-005-MY3 and MOST-108-2112-M-018-004.

Data Availability Statement: The data that support the findings of this study are available from the corresponding author upon reasonable request.

Conflicts of Interest: The authors declare no conflict of interest.

\title{
References
}

1. Vurgaftman, I.; Meyer, J.R. Band parameters for nitrogen-containing semiconductors. J. Appl. Phys. 2003, 94, 3675. [CrossRef]

2. Kneissl, M.; Kolbe, T.; Chua, C.; Kueller, V.; Lobo, N.; Stellmach, J.; Knauer, A.; Rodriguez, H.; Einfeldt, S.; Yang, Z.; et al. Advances in group III-nitride-based deep UV light-emitting diode technology. Semicond. Sci. Technol. 2011, 26, 014036. [CrossRef]

3. Grandusky, J.R.; Gibb, S.R.; Mendrick, M.C.; Moe, C.; Wraback, M.; Schowalter, L.J. High Output Power from 260 nm Pseudomorphic Ultraviolet Light-Emitting Diodes with Improved Thermal Performance. Appl. Phys. Express 2011, $4,082101$. [CrossRef]

4. Park, J.S.; Kim, J.K.; Cho, J.; Seong, T.Y. Review—Group III-Nitride-Based Ultraviolet Light-Emitting Diodes: Ways of Increasing External Quantum Efficiency. ECS J. Solid State Sci. Technol. 2017, 6, Q42. [CrossRef]

5. Li, J.; Nam, K.B.; Nakarmi, M.L.; Lin, J.Y.; Jiang, H.X.; Carrier, P.; Wei, S.H. Band structure and fundamental optical transitions in wurtzite AlN. Appl. Phys. Lett. 2003, 83, 5163. [CrossRef]

6. Kawanishi, H.; Senuma, M.; Yamamoto, M.; Niikura, E.; Nukui, T. Extremely weak surface emission from (0001) c-plane AlGaN multiple quantum well structure in deep-ultraviolet spectral region. Appl. Phys. Lett. 2006, 89, 081121. [CrossRef]

7. Chen, Z.; Zhang, X.; Dou, Z.; Wei, T.; Liu, Z.; Qi, Y.; Ci, H.; Wang, Y.; Li, Y.; Chang, H.; et al. High-Brightness Blue Light-Emitting Diodes Enabled by a Directly Grown Graphene Buffer Layer. Adv. Mater. 2018, 30, 1801608. [CrossRef]

8. Wang, P.; Pandey, A.; Gim, J.; Shin, W.J.; Reid, E.T.; Laleyan, D.A.; Sun, Y.; Zhang, D.; Liu, Z.; Zhong, Z.; et al. Graphene-assisted molecular beam epitaxy of AlN for AlGaN deep-ultraviolet light-emitting diodes. Appl. Phys. Lett. 2020, 116, 171905. [CrossRef]

9. Kim, D.Y.; Park, J.H.; Lee, J.W.; Hwang, S.; Oh, S.J.; Kim, J.; Sone, C.; Schubert, E.F.; Kim, J.Y. Overcoming the fundamental lightextraction efficiency limitations of deep ultraviolet light-emitting diodes by utilizing transverse-magnetic-dominant emission. Light-Sci. Appl 2015, 4, e263. [CrossRef]

10. Kashima, Y.; Maeda, N.; Matsuura, E.; Jo, M.; Iwai, T.; Morita, T.; Kokubo, M.; Tashiro, T.; Kamimura, R.; Osada, Y.; et al. High external quantum efficiency (10\%) AlGaN-based deep-ultraviolet light-emitting diodes achieved by using highly reflective photonic crystal on p-AlGaN contact layer. Appl. Phys. Express 2018, 11, 012101. [CrossRef]

11. Chen, Q.; Zhang, H.; Dai, J.; Zhang, S.; Wang, S.; He, J.; Liang, R.; Zhang, Z.-H.; Chen, C. Enhanced the Optical Power of AlGaN-Based Deep Ultraviolet Light-Emitting Diode by Optimizing Mesa Sidewall Angle. IEEE Photon J. 2018, $10,6100807$. [CrossRef]

12. Mehnke, F.; Kuhn, C.; Stellmach, J.; Kolbe, T.; Lobo-Ploch, N.; Rass, J.; Rothe, M.-A.; Reich, C.; Ledentsov, N., Jr.; Pristovsek, M.; et al. Effect of heterostructure design on carrier injection and emission characteristics of $295 \mathrm{~nm}$ light emitting diodes. J. Appl. Phys. 2015, 117, 195704. [CrossRef]

13. Guttmann, M.; Höpfner, J.; Reich, C.; Sulmoni, L.; Kuhn, C.; Röder, P.; Wernicke, T.; Kneissl, M. Effect of quantum barrier composition on electro-optical properties of AlGaN-based UVC light emitting diodes. Semicond. Sci. Technol. $2019,34,085007$. [CrossRef]

14. Kuo, Y.-K.; Chang, J.-Y.; Chen, F.-M.; Shih, Y.-H.; Chang, H.-T. Numerical Investigation on the Carrier Transport Characteristics of AlGaN Deep-UV Light-Emitting Diodes. IEEE J. Quantum Electron. 2016, 52, 3300105. [CrossRef]

15. Chang, J.-Y.; Huang, M.-F.; Chen, F.-M.; Liou, B.-T.; Shih, Y.-H.; Kuo, Y.-K. Effects of quantum barriers and electron-blocking layer in deep-ultraviolet light-emitting diodes. J. Phys. D Appl. Phys. 2018, 51, 075106. [CrossRef]

16. Chang, J.-Y.; Liou, B.-T.; Huang, M.-F.; Shih, Y.-H.; Chen, F.-M.; Kuo, Y.-K. High-Efficiency Deep-Ultraviolet Light-Emitting Diodes with Efficient Carrier Confinement and High Light Extraction. IEEE Trans. Electron Devices 2019, 66, 976. [CrossRef]

17. APSYS, Crosslight Software. Vancouver, BC, Canada. 2015. Available online: http:/ / www.crosslight.com (accessed on 27 January 2021).

18. Yan, J.; Wang, J.; Zhang, Y.; Cong, P.; Sun, L.; Tian, Y.; Zhao, C.; Li, J.J. AlGaN-based deep-ultraviolet light-emitting diodes grown on High-quality AIN template using MOVPE. Cryst. Growth 2015, 414, 254. [CrossRef]

19. Ryu, H.Y.; Kim, H.S.; Shim, J.I. Rate equation analysis of efficiency droop in InGaN light-emitting diodes. Appl. Phys. Lett. 2009, 95, 081114. [CrossRef]

20. Piprek, J.; Li, Z.S. Band offsets and heterostructures of two-dimensional semiconductors. Appl. Phys. Lett. 2013, 102, 0235100. 
21. Kuo, Y.-K.; Chang, J.-Y.; Chang, H.-T.; Chen, F.-M.; Shih, Y.-H.; Liou, B.-T. Polarization Effect in AlGaN-Based Deep-Ultraviolet Light-Emitting Diodes. IEEE J. Quantum Electron. 2017, 53, 3300106. [CrossRef]

22. Miller, D.A.B.; Chemla, D.S.; Damen, T.C. Band-Edge Electroabsorption in Quantum Well Structures: The Quantum-Confined Stark Effect. Phys. Rev. Lett. 1984, 53, 2173. [CrossRef]

23. Kuo, Y.-K.; Chang, J.-Y.; Tsai, M.-C.; Yen, S.-H. Advantages of blue InGaN multiple-quantum well light-emitting diodes with InGaN barriers. Appl. Phys. Lett. 2009, 95, 011116. [CrossRef] 